\title{
DETERMINASI KOMPENSASI, LINGKUNGAN KERJA, DAN KOMITMEN ORGANISASI TERHADAP KINERJA PEGAWAI NEGERI SIPIL DINAS PENDAPATAN DAERAH PROVINSI KEPULAUAN RIAU
}

\author{
Surya Akbar, Syafrijon Aripah dan Benny Asmali Indra \\ Program Studi Ilmu Administrasi Negara STIA Indragiri \\ Jl. Azki Aris, Rengat. Kode Pos 29318. Telp. (0769) 22458
}

\section{ABSTRACT}

This study describes the purpose Determination of Compensation, Work Environtment and Organizational Commitment Of Performance Employee On Province Riau Islands Department of Revenue Services.

The research method used survey method, in which the respondent as many as 80 people as population and drawn sample of 91 people with a sample proportional random sampling method using Slovin formula with looseness rate of $5 \%$. Collection of data techniques using the instrument from the questionnaire form for variable analsisis.

These results indicate that compensation determination significant on performance employee, work environment determination significant on performance employee and organizational commitment variables determination significant on performance employee. While simultaneously discovered that there is significant influence between three variables of compensation, work environment and organizational commitment of performance employee .

Keywords: Compensation, Work Environment, and Organizational Commitment, Performance Employee. 


\section{PENDAHULUAN}

\section{Latar Belakang}

Dinas Pendapatan Daerah Provinsi Kepulauan Riau terbentuk berdasarkan Peraturan Daerah No. 4 Tahun 2011 tentang Organisasi dan Tata Kerja Sekretariat Daerah, Sekretariat DPRD dan Dinas Daerah Provinsi Kepulauan Riau Provinsi Kepulauan Riau.

Dinas Pendapatan Daerah merupakan unsur pelaksana Pemerintah Provinsi di bidang pendapatan daerah sesuai dengan kewenangan Pemerintah Provinsi serta peraturan perundang - undangan. Memiliki tugas melaksanakan sebagian kewenangan desentralisasi, tugas dekonsentrasi dan tugas pembantuan di bidang pendapatan daerah sesuai lingkup tugasnya.

Untuk mendukung pelaksanaan tersebut dalam rangka merespon perubahan, tantangan kemajuan dan tuntutan kebutuhan masyarakat diperlukan adanya sumber daya aparat birokrasi berkualitas dan sumber dana yang memadai serta dukungan partisipasi masyarakat yang terus meningkat.

Dengan era globalisasi ditambah adanya krisis ekonomi moneter dan menurunnya kepercayaan masyarakat terhadap pemerintah yang berkepanjangan melanda negara kita sampai saat ini belum bisa teratasi secara baik, sebagai akumulasi permasalahan yang dihadapi oleh bangsa dan negara akan menjadi hambatan dan tantangan dalam penyelenggaraan pemerintahan dan pembangunan di daerah.

Semakin berkembangnya tingkat perekonomian dan teknologi di Kepulauan Riau dan meningkatnya kebutuhan pendanaan dalam penyelenggaraan pemerintahan, Dinas Pendapatan Daerah dituntut untuk menyediakan kualitas data - data yang akurat dan harus dapat dipertanggung jawabkan kepada masyarakat, dan rakyat sebagai pemegang kedaulatan tertinggi Negara sesuai dengan peraturan dan ketentuan yang berlaku.

Oleh karena itu pemerintah daerah dituntut untuk bersifat inovatif dan kreatif. Tentunya dalam menggali dan mengelola sumber pembiayaan penyelenggaraan pemerintah dan pembangunan bagi daerahnya. Otonomi daerah yang pada prinsipnya bermakna kemandirian, mengharuskan daerah kabupaten dan kota mengelola 
kelangsungan hidupnya atas kemampuan sendiri, berkembang secara dinamis dan memenuhi segenap kemandirian itu.

Dalam rangka menyajikan data yang akurat dan akuntabilitas, maka dibutuhkan sumber daya manusia yang berkualitas dan loyalitas yang tinggi. Sebuah organisasi harus mampu untuk meningkatkan kemampuan sumber daya manusia yang dimilikinya agar pencapaian tujuan dapat terlaksana. Sumber daya manusia merupakan salah satu bagian dari kemajuan ilmu pengetahuan dan teknologi, serta ilmu manajemen yang lebih fokus kepada pengaturan peranan sumber daya manusia di dalam organisasi.

Dengan kemajuan teknologi sekarang sumber daya manusia dituntut untuk memiliki kinerja dan ketrampilan kerja dalam menjalankan peran dan fungsinya, baik untuk individual maupun tujuan organisasi. Selain itu juga diharapkan mampu meningkatkan kualitas dalam memberikan pelayanan kepada masyarakat.

Mengingat pentingnya determinasi kompensasi, lingkungan kerja dan komitmen organisasi terhadap meningkatnya kinerja pegawai, dimana kinerja pegawai akan menentukan ketercapaian tujuan organisasi.

Tabel 1 Tingkat Absensi Pegawai Negeri Sipil Dispenda Prov. Kepri Tahun 2016

\begin{tabular}{|c|c|c|c|}
\hline \multirow{2}{*}{ Bulan } & $\begin{array}{c}\text { Jumlah Pegawai } \\
\text { (orang) }\end{array}$ & $\begin{array}{c}\text { Absensi/Tidak } \\
\text { Hadir }\end{array}$ & Terlambat \\
\cline { 2 - 4 } & 118 & $\mathbf{( \% )}$ & $\mathbf{( \% )}$ \\
\hline Februari & 118 & 9,1 & 9,2 \\
\hline Maret & 118 & 9,6 & 9,3 \\
\hline April & 118 & 9,8 & 9,6 \\
\hline Mei & 118 & 9,0 & 9,5 \\
\hline Juni & 9,0 & 8,9 \\
\hline
\end{tabular}

Sumber: Dispenda Prov. Kepri, 2016

Pada Tabel 1.1 di atas dapat diidentifikasi suatu permasalahan terpenting adalah bahwa belum optimalnya kinerja dari pegawai Dispenda Kepri yang dituntut untuk bekerja secara profesional dan optimal dalam melayani masyarakat. Penurunan kinerja pegawai negeri sipil yang ditandai dengan adanya kecenderungan (trend) 
meningkatnya jumlah pegawai yang absen, terlambat dan cepat pulang. Dengan memperhatikan tingkat absensi pegawai, maka dapat diketahui bahwa semakin tinggi tingkat absensi menunjukan rendahnya kinerja pegawai. Untuk itu saya sangat tertarik untuk meneliti kinerja pegawai di Dinas Pendapatan Daerah Provinsi Kepulauan Riau.

Berdasarkan persoalan-persoalan dalam uraian tersebut, maka penelitian ini bertujuan untuk melihat seberapa besar pengaruh ketiga variabel berupa kompensasi, lingkungan kerja dan komitmen organisasi terhadap kinerja pegawai negeri sipil Dinas Pendapatan Daerah Propinsi Kepulauan Riau.

Oleh karena itu berdasarkan latar belakang yang penulis uraikan tersebut, maka penulis tertarik untuk mengangkat judul penelitian ini dengan judul

\section{"Determinasi Kompensasi, Lingkungan Kerja dan Komitmen Organisasi Terhadap Kinerja Pegawai Negeri Sipil Dinas Pendapatan Daerah Provinsi Kepulauan Riau". \\ Identifikasi Masalah}

Dengan belum optimalnya kinerja para pegawai negeri sipil di lingkungan Dinas Pendapatan Daerah Provinsi Kepulauan Riau yang dituntut untuk bekerja secara profesional dalam melayani masyarakat, dan menurunnya kinerja pegawai negeri sipil yang ditandai dengan tingkat kehadiran rendah dan meningkatnya jumlah absensi.

\section{Rumusan Masalah}

Adapun rumusan masalah tersebut dapat diuraikan sebagai berikut:

1. Apakah kompensasi determinasi terhadap kinerja pegawai negeri sipil di lingkungan Dinas Pendapatan Daerah Provinsi Kepulauan Riau?

2. Apakah lingkungan kerja determinasi terhadap kinerja pegawai negeri sipil di lingkungan Dinas Pendapatan Daerah Provinsi Kepulauan Riau?

3. Apakah komitmen organisasi determinasi terhadap kinerja pegawai negeri sipil di lingkungan Dinas Pendapatan Daerah Provinsi Kepulauan Riau?

4. Apakah kompensasi, lingkungan kerja dan komitmen organisasi secara bersamasama determinasi terhadap peningkatan kinerja pegawai negeri sipil di lingkungan Dinas Pendapatan Daerah Provinsi Kepulauan Riau?

\section{Batasan Masalah}


Agar penelitian ini dapat memberikan pemahaman yang sesuai dengan apa yang diharapkan, maka penyusunan skripsi ini diadakan pembatasan lingkup penelitian pada pegawai negeri sipil di lingkungan Dinas Pendapatan Daerah Kepulauan Riau yaitu determinasi kompensasi, lingkungan kerja, komitmen organisasi, dan kinerja pegawai negeri sipil.

\section{Tujuan Penelitian}

Penelitian ini memiliki tujuan yang dapat dijelaskan berdasarkan rumusan masalah adalah sebagai berikut:

1. Untuk mengetahui determinasi kompensasi terhadap kinerja pegawai negeri sipil di lingkungan Dinas Pendapatan Daerah Provinsi Kepulauan Riau.

2. Untuk mengetahui determinasi lingkungan kerja terhadap kinerja pegawai negeri sipil di lingkungan Dinas Pendapatan Daerah Provinsi Kepulauan Riau.

3. Untuk mengetahui determinasi komitmen organisasi terhadap kinerja pegawai negeri sipil di lingkungan Dinas Pendapatan Daerah Provinsi Kepulauan Riau.

4. Untuk mengetahui determinasi kompensasi, lingkungan kerja dan komitmen organisasi secara simultan terhadap kinerja pegawai negeri sipil di lingkungan Dinas Pendapatan Daerah Provinsi Kepulauan Riau.

\section{Manfaat Penelitian}

Manfaat dari penelitian ini yaitu diharapkan dapat bermanfaat untuk semua kalangan terutama terhadap obyek yang berhubungan dengan variabel dalam penelitian ini. Adapun rincian manfaatnya adalah sebagai berikut :

1. Manfaat teoritis

a. Sebagai bahan pertimbangan dan referensi dasar bagi Dinas Pendapatan Daerah Provinsi Kepulauan Riau khususnya dalam mengambil langkah langkah kebijakan, terutama untuk bagian sumber daya manusia dalam usaha meningkatkan kualitas aparatur jujur, professional dan terampil yang berkaitan determinasi dengan kompensasi terhadap kinerja pegawai negeri sipil dalam rangka meningkatkan pendapatan daerah

b. Untuk lebih memperjelas pemahaman tentang teori sumber daya manusia terutama yang berhubungan dengan variabel penelitian berupa kompensasi, lingkungan kerja dan komitmen organisasi pegawai negeri sipil terhadap kinerja Dinas Pendapatan Daerah Provinsi Kepulauan Riau. 
c. Bagi peneliti, penelitian ini dapat menambah pengetahuan mengenai determinasi kompensasi, lingkungan kerja dan komitmen organisasi untuk meningkatkan kinerja pegawai di lingkungan Dinas Pendapatan Daerah Provinsi Kepulauan Riau.

d. Bagi pembaca, penelitian ini diharapkan mampu memberikan informasi secara tertulis maupun sebagai referensi mengenai determinasi kompensasi dan lingkungan kerja serta komitmen organisasi merupakan unsur penting dalam meningkatkan kinerja pegawai.

2. Manfaat praktis

Dalam pengambilan kebijakan perlunya mempertimbangkan aspek teoritis berupa penggunaan sumber daya manusia dengan tingkat pengkajian tentang kompensasi, lingkungan kerja dan komitmen organisasi pegawai, terhadap persoalan kinerja pegawai negeri sipil Dinas Pendapatan Daerah Provinsi Kepulauan Riau.

\section{Kerangka Teori}

\section{Pengertian Kompensasi}

Kompensasi menurut Mangkunegara (2013; 83) adalah sesuatu yang dipertimbangkan sebagai suatu yang sebanding, dalam kepegawaian hadiah yang bersifat uang merupakan kompensasi yang diberikan kepada pegawai sebagai penghargaan dari pelayanan mereka.

\section{Pengertian Lingkungan Kerja}

Lingkungan kerja menurut Sedarmayanti (2011; 28) faktor yang dapat mempengaruhi terbentuknya suatu kondisi lingkungan kerja dikaitkan dengan kemampuan manusia atau pegawai, diantaranya adalah penerangan atau cahaya, temperature atau suhu, kelembaban, sirkulasi udara, kebisingan, getaran mekanis, bau tidak sedap, tata warna, dekorasi, musik, keamanan.

\section{Pengertian Komitmen Organisasi}

Komitmen organisasi menurut Meyer and Allen dalam Luthans (2006; 249) bahwa ada tiga komponen komitmen organisasional yaitu (i) komitmen afektif (affective commitment), (ii) komitmen kelanjutan (continuance commitment), (iii) komitmen normatif (normative commitment).

\section{Model Penelitian}




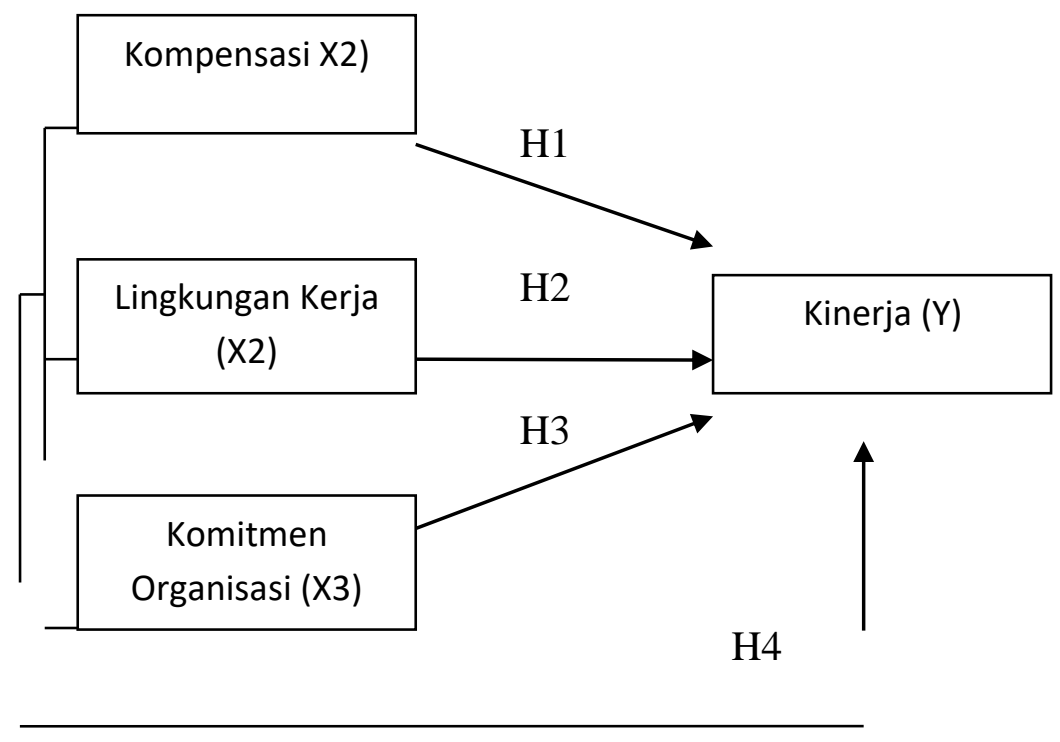

Gambar 1. Kerangka Berfikir

\section{Hipotesis}

Adapun hipotesis yang dapat diungkapkan berdasarkan dari kerangka berfikir tersebut dijelaskan sebagai berikut:

1. Determinasi kompensasi terhadap kinerja pegawai negeri sipil Dispenda Kepulauan Riau.

2. Determinasi lingkungan kerja terhadap kinerja pegawai negeri sipil Dispenda Kepulauan Riau.

3. Determinasi komitmen organisasi terhadap kinerja pegawai negeri sipil Dispenda Kepulauan Riau.

4. Determinasi kompensasi, lingkungan kerja dan komitmen organisasi terhadap kinerja pegawai negeri sipil Dispenda Kepulauan Riau.

\section{Populasi dan Sampel}

\section{Populasi}

Populasi adalah sekelompok orang, kejadian, sesuatu yang mempunyai karakteristik tertentu. (Rumengan, 2010; 45).

Dalam penelitian ini populasinya adalah semua pegawai yang bertugas di Dinas Pendapatan Daerah Provinsi Kepulauan Riau yang terdiri dari berbagai bidang, dengan jumlah populasi sebanyak 91 orang.

\section{Sampel}


Sampel adalah bagian dari populasi dengan karakteristik yang dianggap mewakili populasi penelitian. (Rumengan, 2010; 45). Sampel merupakan sebagian atau wakil dari populasi yang diteliti. Sampel yang digunakan dalam penelitian ini adalah "proportional stratified random sampling" digunakan bila populasi mempunyai anggota/unsur yang tidak homogen dan berstrata secara proporsional.

\section{Teknik Pengolahan Data}

\section{Uji Validitas dan Reliabilitas}

Instrumen yang dicapai apabila data yang dihasilkan dari isntrumen tersebut sesuai dengan data atau informasi lain yang mengenai variabel penelitian yang dimaksud (Sunyoto, 2011: 69), Reliabilitas menunjukkan pada tingkat keterandalan sesuatu. Reliabel artinya, dapat dipercaya jadi dapat diandalkan. (Suharsimi, 2006 dalam Sunyoto, 2011: 70).

\section{Analisis Regresi Linear Berganda}

Analisis regresi linear berganda digunakan untuk mengukur pengaruh antara lebih dari satu variable prediktor (bebas) terhadap variable terikat, $\mathbf{Y}=\alpha+\mathbf{b}_{1} \mathbf{X}_{1}+\mathbf{b}_{2} \mathbf{X}_{2}+\mathbf{b}_{3} \mathbf{X}_{3}+e$

\section{Uji Hipotesis}

Uji Parsial (Uji t) dipakai untuk melihat signifikansi pengaruh, variabel independen secara individu terhadap variabel dependen dengan menganggap variabel lain bersifat konstan.

Uji Simultan (Uji F) dipakai untuk melihat pengaruh variabel-variabel independen secara keseluruhan terhadap variabel dependen.

Analisis Koefisien Determinasi $\left(\mathrm{R}^{2}\right)$ semakin besar $\mathrm{R}^{2}$ (mendekati 1), semakin baik model regresi tersebut.

\section{ANALISIS DAN PEMBAHASAN}

\section{Gambaran Umum Dispenda Kepri}

Kepala Dispenda Provinsi Kepulauan Riau pertama adalah Drs. H. Amhar Ismail, M. Si., Drs. Naharuddin, M. TP. Dan yang sekarang adalah H. Isdianto S.Sos, MM selaku Kepala Dinas Pendapatan Daerah Provinsi Kepulauan Riau saat ini. Agustus 2004 adalah awal Dispenda Provinsi Kepulauan Riau dalam melaksanakan berbagai kegiatan yang menjadi tugas pokok dan fungsi serta tugas pemerintahan 
daerah selaku instansi yang berwenang untuk melaksanakan pemungutan Pendapatan Daerah serta melaksanakan pemungutan Pajak Daerah dan Retribusi Daerah sebagaimana yang tercantum dalam Undang-Undang Nomor 28 Tahun 2009 Tentang Pajak Daerah dan Retribusi Daerah dengan wilayah kerja mencakup Kota Batam, Kota Tanjung Pinang, Kabupaten Bintan, Kijang, Kabupaten Tanjung Balai Karimun, Kabupaten Natuna, Kabupaten Anambas, Tanjung Batu, dan Kabupaten Lingga.

\section{DEMOGRAFI RESPONDEN}

Diketahui bahwa responden laki-laki sebanyak 45 orang 56,25\%, sedangkan responden perempuan sebanyak 35 orang 43,75\%. Responden tingkat pendidikan SLTA adalah sebanyak 14 responden 17,5\%, D3 sebanyak 9 responden 11,25\%, Sarjana S1 sebanyak 48 responden 60\%, dan Sarjana S2 sebanyak 9 responden. Responden golongan kepangkatan Gol III adalah 50 responden 62,5\%, dan Gol II adalah 30 responden $37,5 \%$.

\section{HASIL PENGUJIAN}

\section{Analisis Validitas}

Tabel 2 Hasil Validitas

\begin{tabular}{ccc}
\hline Item & Nilai Korelasi & Keterangan \\
\hline X1.1 & 0,842 (Positif) & Valid \\
X1.2 & 0,847 (Positif) & Valid \\
X1.3 & 0,875 (Positif) & Valid \\
X1.4 & 0,833 (Positif) & Valid \\
X1.5 & 0,865 (Positif) & Valid \\
X1.6 & 0,832 (Positif) & Valid \\
X1.7 & 0,906 (Positif) & Valid \\
X1.8 & 0,882 (Positif) & Valid \\
X1.9 & 0,854 (Positif) & Valid \\
X2.1 & 0,709 (Positif) & Valid \\
X2.2 & 0,772 (Positif) & Valid \\
X2.3 & 0,757 (Positif) & Valid \\
\hline
\end{tabular}




\begin{tabular}{|c|c|c|}
\hline $\mathrm{X} 2.4$ & 0,797 (Positif) & Valid \\
\hline $\mathrm{X} 2.5$ & 0,737 (Positif) & Valid \\
\hline $\mathrm{X} 2.6$ & 0,809 (Positif) & Valid \\
\hline $\mathrm{X} 2.7$ & 0,712 (Positif) & Valid \\
\hline $\mathrm{X} 2.8$ & 0,785 (Positif) & Valid \\
\hline $\mathrm{X} 2.9$ & 0,836 (Positif) & Valid \\
\hline X3.1 & 0,760 (Positif) & Valid \\
\hline $\mathrm{X} 3.2$ & 0,727 (Positif) & Valid \\
\hline X3.3 & 0,764 (Positif) & Valid \\
\hline X3.4 & 0,686 (Positif) & Valid \\
\hline $\mathrm{X} 3.5$ & 0,796 (Positif) & Valid \\
\hline X3.6 & 0,829 (Positif) & Valid \\
\hline X3.7 & 0,356 (Positif) & Valid \\
\hline $\mathrm{X} 3.8$ & 0,510 (Positif) & Valid \\
\hline X3.9 & 0,378 (Positif) & Valid \\
\hline Y.1 & 0,884 (Positif) & Valid \\
\hline Y.2 & 0,822 (Positif) & Valid \\
\hline Y.3 & 0,714 (Positif) & Valid \\
\hline Y.4 & 0,767 (Positif) & Valid \\
\hline Y.5 & 0,687 (Positif) & Valid \\
\hline Y.6 & 0,814 (Positif) & Valid \\
\hline Y.7 & 0,884 (Positif) & Valid \\
\hline Y.8 & 0,321 (Positif) & Valid \\
\hline Y.9 & 0,426 (Positif) & Valid \\
\hline
\end{tabular}

Sumber: Diolah dari data primer 2016

Berdasarkan pengujian validitas diketahui bahwa seluruh butir pernyataan yang digunakan adalah valid, hal ini ditunjukkan dari nilai $r_{h i t u n g}>r_{\text {tabel }}$ dimana $r$ hitung (sesuai lampiran hasil output) bernilai diatas nilai yang telah disyaratkan dalam penelitian yaitu 0,2 .

\section{Analisis Reliabilitas}

Tabel 3 Hasil Reliabilitas 


\begin{tabular}{ccc}
\hline Variabel & Alpha $(\alpha)$ & Status \\
\hline Kompensasi $\left(\mathrm{X}_{1}\right)$ & 0,954 & Reliabel \\
Lingkungan Kerja $\left(\mathrm{X}_{2}\right)$ & 0,912 & Reliabel \\
Komitmen Organisasi $\left(\mathrm{X}_{3}\right)$ & 0,814 & Reliabel \\
Kinerja Pegawai $(\mathrm{Y})$ & 0,883 & Reliabel \\
\hline
\end{tabular}

Sumber: Diolah dari data primer 2016

Berdasarkan Tabel 3 di atas dapat diketahui bahwa seluruh hasil cronbach alpha $>0,60$, maka nilai yang didapatkan reliable.

Tabel 4 Uji Multikolinieritas

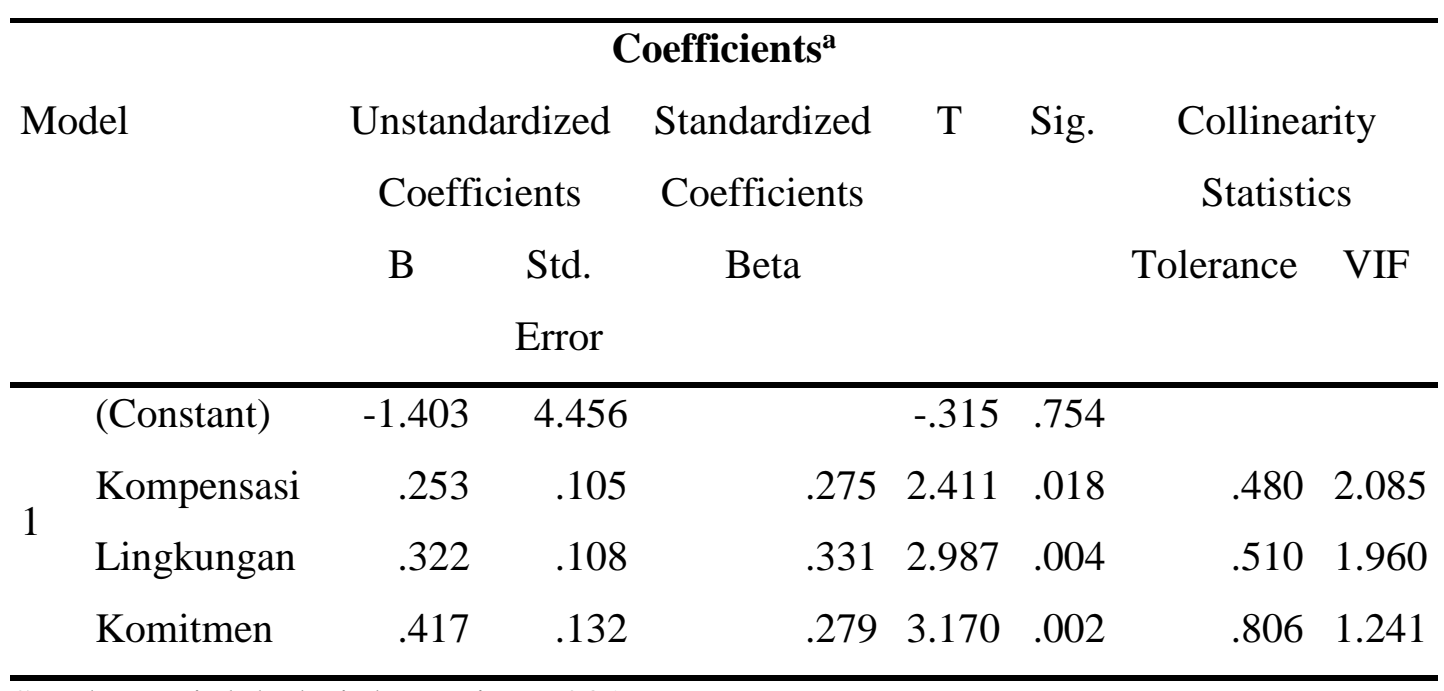

Sumber: Diolah dari data primer 2016

Berdasarkan tabel 4 di atas ke tiga independen yaitu kompensasi, lingkungan kerja dan komitmen organisasi memiliki nilai VIF $<$ dari 10,00 , sehingga dapat disimpulkan bahwa antara variabel independen tidak terjadi multikolinieritas.

Tabel 5 Hasil Uji Analisis Regresi Linear Berganda

\begin{tabular}{lcccccc}
\hline \multirow{2}{*}{ Model } & \multicolumn{5}{c}{ Coefficients $^{\mathbf{a}}$} \\
& Unstandardized & Standardized & $\mathrm{T}$ & Sig. & Collinearity \\
& Coefficients & Coefficients & & & Statistics \\
& B & Std. & Beta & & Tolerance VIF \\
& \multicolumn{3}{c}{ Error } & & & \\
\hline 1 & (Constant) & -1.403 & 4.456 & & -.315 & .754 \\
\hline
\end{tabular}




\begin{tabular}{llllllll}
\hline Kompensasi & .253 & .105 & .275 & 2.411 & .018 & .480 & 2.085 \\
Lingkungan & .322 & .108 & .331 & 2.987 & .004 & .510 & 1.960 \\
Komitmen & .417 & .132 & .279 & 3.170 & .002 & .806 & 1.241 \\
\hline
\end{tabular}

Sumber: Diolah dari data primer 2016

Berdasarkan tabel 5 di atas di dapatkan hasil persamaan regresi linier berganda sebagai berikut: $Y=-1,403+0,253 X_{1}+0,322 X_{2}+0,417 X_{3}+e$

Dari persamaan di atas dapat diinterprestasikan sebagai berikut:

$\alpha=-\mathbf{1 , 4 0 3}$

Nilai konstanta bernilai negatif $(-1,403)$ artinya apabila Kompensasi $\left(\mathrm{X}_{1}\right)$ dan Lingkungan Kerja $\left(\mathrm{X}_{2}\right)$ dan Komitmen Organisasi $\left(\mathrm{X}_{3}\right)$ nilainya sama dengan nol, maka Kinerja Pegawai Negeri Sipil akan semakin berkurang.

$b_{1}=0,253$

Koefisien regresi untuk variabel Kompensasi $\left(\mathrm{X}_{1}\right)$ sebesar 0,253 artinya jika Kompensasi $\left(\mathrm{X}_{1}\right)$ meningkat satu satuan maka Kinerja Pegawai Negeri Sipil akan meningkat 0,253 .

$\mathbf{b}_{2}=\mathbf{0 , 3 2 2}$

Koefisien regresi untuk variabel Lingkungan Kerja $\left(\mathrm{X}_{2}\right)$ sebesar 0,322 artinya jika Lingkungan Kerja $\left(\mathrm{X}_{2}\right)$ meningkat satu satuan maka Kinerja Pegawai Negeri Sipil akan meningkat 0,322 .

$\mathbf{b}_{3}=\mathbf{0 , 4 1 7}$

Koefisien regresi untuk variabel Komitmen Organisasi $\left(\mathrm{X}_{3}\right)$ sebesar 0,417 artinya jika Komitmen Organisasi $\left(\mathrm{X}_{3}\right)$ meningkat satu satuan maka Kinerja Pegawai Negeri Sipil akan meningkat 0,417.

\section{HASIL PENGUJIAN HIPOTESIS}

Tabel 6 Uji t (parsial)

\section{Coefficients $^{\mathrm{a}}$}

$\begin{array}{ccccc}\text { Model Unstandardized } & \text { Standardized } & \text { T } & \text { Sig. } & \text { Collinearity } \\ \text { Coefficients } & \text { Coefficients } & \text { Statistics } \\ \text { B Std. } & \text { Beta } & \text { Tolerance VIF } \\ \text { Error } & & \end{array}$




\begin{tabular}{llrrrrrrr}
\hline & (Constant) & -1.403 & 4.456 & & -.315 & .754 & & \\
1 & Kompensasi & .253 & .105 & .275 & 2.411 & .018 & .480 & 2.085 \\
& Lingkungan & .322 & .108 & .331 & 2.987 & .004 & .510 & 1.960 \\
& Komitmen & .417 & .132 & .279 & 3.170 & .002 & .806 & 1.241 \\
\hline
\end{tabular}

Sumber: Diolah dari data primer 2016

Dari hasil pengujian variabel bebas Kompensasi, Lingkungan Kerja dan Komitmen Organisasi terhadap Kinerja Pegawai Negeri Sipil dengan derajat kebebasannya $\mathrm{n}-(\mathrm{k}-1)=80-3-1=76, \mathrm{t}_{\text {tabel }}=1,991$, dijelaskan sebagai berikut :

1. Variabel Kompensasi $\left(\mathrm{X}_{1}\right)$ ditunjukkan dengan nilai thitung sebesar 2,411 lebih besar dari $\mathrm{t}_{\text {tabel }}=1,991, \mathrm{t}_{\text {hitung }}>\mathrm{t}_{\text {tabel }}$ yang berarti kompensasi determinasi signifikan terhadap kinerja pegawai negeri sipil dan nilai signifikansi 0,018 lebih besar dari 0,05 $(0,018<0,05)$.

2. Variabel Lingkungan Kerja $\left(X_{2}\right)$ ditunjukkan dengan nilai dengan nilai thitung sebesar 2,987 lebih besar dari tabel $=1,991$ berarti lingkungan kerja determinasi signifikan terhadap kinerja pegawai negeri sipil, dan nilai signifikansi 0,004 lebih kecil dari $0,05(0,004<0,05)$

3. Variabel Komitmen Organisasi $\left(\mathrm{X}_{3}\right)$ ditunjukkan dengan nilai dengan nilai thitung sebesar 3,170 lebih besar dari $t_{\text {tabel }}=1,991$ yang berarti komitmen organisasi determinasi signifikan terhadap kinerja pegawai negeri sipil, dan nilai signifikansi 0,002 lebih kecil dari $0,05(0,002<0,05)$.

Tabel 7 Hasil Uji F (Simultan)

\begin{tabular}{|c|c|c|c|c|c|c|}
\hline \multicolumn{7}{|c|}{ ANOVA $^{a}$} \\
\hline \multicolumn{2}{|l|}{ Model } & Sum of & df & Mean Square & $\mathrm{F}$ & Sig. \\
\hline \multirow{3}{*}{1} & Regression & 1197.948 & 3 & 399.316 & 27.913 & $.000^{\mathrm{b}}$ \\
\hline & Residual & 1087.252 & 76 & 14.306 & & \\
\hline & Total & 2285.200 & 79 & & & \\
\hline
\end{tabular}

Sumber: Diolah dari data primer 2016

Pengujian hipotesis pertama dengan $\alpha=5 \%$ diperoleh nilai $\mathrm{F}_{\text {hitung }}=27,913$ sedangkan nilai $F_{\text {tabel }}=2,70$. Jadi $\mathbf{F}_{\text {hitung }}>\mathbf{F}_{\text {tabel}}$, dan probabilitas (sig) sebesar $0,000<0,05$ sehingga $\mathrm{H}_{0}$ ditolak. Jadi secara bersama-sama (simultan) variabel 
Kompensasi, Lingkungan Kerja dan Komitmen Organisasi determinasi signifikan terhadap Kinerja Pegawai Negeri Sipil.

Analisis Koefisien Determinasi $\left(\mathbf{R}^{2}\right)$

Tabel 8 Analisis R-Square

\begin{tabular}{lllrr}
\hline Model & R & R Square & Adjusted R Square & $\begin{array}{c}\text { Durbin- } \\
\text { Watson }\end{array}$ \\
& & & & \\
\hline 1 & $.724^{\mathrm{a}}$ & .524 & .505 & 1.315 \\
\hline
\end{tabular}

Sumber: Diolah dari data primer 2016

Dan dari hasil penelitian ini maka diketahui nilai $\mathrm{R}$ adalah sebesar 0,724 $(72,4 \%)$ sedangkan nilai $\mathrm{R}^{2}$ adalah sebesar 0,524 . Dari nilai tersebut dapat dilihat bahwa Kinerja Pegawai Negeri Sipil dipengaruhi oleh Kompensasi, Lingkungan Kerja dan Komitmen Organisasi sebesar 0,524 atau sebesar 52,4\%, sedangkan sisanya sebesar $47,6 \%$ dipengaruhi oleh faktor-faktor lain yang tidak diteliti dalam penelitian ini.

\section{Kesimpulan}

Dari hasil penelitian dan pembahasan yang telah dijelaskan dan diuji pada bab sebelumnya dapat diambil kesimpulan sebagai berikut:

1. Dari hasil uji secara parsial terhadap variabel penelitian antara kompensasi terhadap kinerja pegawai negeri sipil didapat nilai thitung sebesar 2,411 lebih besar dari $t_{\text {tabel }}=1,991$ berarti signifikan terhadap kinerja pegawai negeri sipil dan nilai signifikansi 0,018 lebih kecil dari 0,05. Jadi secara parsial variabel kompensasi determinasi signifikan terhadap kinerja pegawai.

2. Dari hasil uji secara parsial terhadap variabel penelitian antara lingkungan kerja terhadap kinerja pegawai negeri sipil didapat nilai $t_{\text {hitung }}$ sebesar 2,987 lebih besar dari $t_{\text {tabel }}=1,991$ berarti signifikan terhadap kinerja pegawai negeri sipil dan nilai signifikansi 0,004 lebih kecil dari 0,05. Jadi secara parsial variabel lingkungan kerja determinasi signifikan terhadap kinerja pegawai negeri sipil.

3. Dari hasil uji yang telah dilakukan terhadap variabel penelitian antara komitmen organisasi terhadap kinerja pegawai negeri sipil didapat nilai thitung sebesar 3,170 lebih besar dari $t_{\text {tabel }}=1,991$ berarti signifikan terhadap kinerja pegawai dan nilai 
signifikansi 0,002 lebih kecil dari 0,05. Jadi secara parsial variabel komitmen organisasi determinasi signifikan terhadap kinerja pegawai negeri sipil.

4. Dari hasil uji yang telah dilakukan terhadap variabel penelitian antara kompensasi, lingkungan kerja dan komitmen organisasi terhadap kinerja pegawai negeri sipil maka kesimpulannya adalah determinasi positif dan signifikan antara kompensasi, lingkungan kerja dan komitmen organisasi secara bersama-sama atau simultan terhadap kinerja pegawai dengan nilai $F_{\text {hitung }}=27,913$ sedangkan nilai $\mathrm{F}_{\text {tabel }}=2,72$. Jadi $\mathrm{F}_{\text {hitung }}>\mathrm{F}_{\text {tabel, }}$ dan probabilitas $(\mathrm{sig})$ sebesar $0,000<0,05$ sehingga $\mathrm{H}_{0}$ ditolak. Jadi secara bersama-sama (simultan) variabel kompensasi, lingkungan kerja dan komitmen organisasi determinasi signifikan terhadap kinerja pegawai negeri sipil pada Dispenda Kepri.

\section{Saran}

Adapun saran yang dapat diberikan dalam upaya peningkatan kinerja pegawai Dispenda Kepulauan Riau adalah sebagai berikut:

1. Hasil penelitian mengenai Kompensasi pada Dispenda Kepulauan Riau determinasi signifikan terhadap kinerja pegawai negeri sipil, yang terjadi selama ini bahwa kompensasi diberikan kurang memperhatikan kinerja pegawai negeri sipil. Maka dalam mengatasi hal tersebut diperlukan adanya upaya dan usaha perbaikan sistem maupun aturan yang diterapkan baik dari pihak pimpinan maupun organisasi dalam rangka untuk meningkatkan kinerja pegawai negeri sipil.

2. Hasil penelitian mengenai lingkungan kerja pada Dispenda Kepulauan Riau memiliki indikator yang memberikan determinasi secara signifikan terhadap kinerja pegawai negeri sipil. Oleh itu pegawai negeri sipil di lingkungam Dispenda Prov. Kepri harus mempertahankan dan meningkatkan lingkungan kerja, baik di dalam dan di luar organisasi serta berkomunikasi lebih baik lagi sesama rekan kerja dan atasan, dan juga mentaati setiap peraturan yang digunakan sebagai pedoman dalam melakukan pekerjaan.

3. Komitmen Organisasi determinasi signifikan terhadap kinerja, dan dalam penelitian ini memiliki indikator sangat baik, sehingga perlu terus dipelihara dan dipertahankan untuk menciptakan iklim kerja yang kondusif dimana antara pimpinan dan pegawainya saling mendukung satu sama lain. 
4. Kinerja pegawai negeri sipil pada Dispenda Kepulauan Riau sudah baik. Oleh karena itu pegawai negeri sipil diharapkan untuk meningkatkan disiplin, bekerja sesuai dengan target yang telah ditentukan, dan mempertahankan serta meningkatkan komitmen organisasi untuk keberhasilan dalam menyelesaikan pekerjaan dengan penuh tanggung jawab.

\section{DAFTAR PUSTAKA}

Kaswan. 2012. Manajemen Sumber Daya Manusia untuk Keunggulan Bersaing Organisasi Cetakan Pertama. Yogyakarta : Graha Ilmu

Luthans. Fred. 2006. Perilaku Organisasi Edisi 10. Yogyakarta : Andi

Mangkunegara. 2013. Manajemen Sumber Daya Manusia Perusahaan. Bandung : PT. Remaja Rosdakarya

Rumengan. Jeremy. 2010. Metodologi Penelitian dengan SPSS. Batam : Uniba Press

Sedarmayanti. 2011. Tata Kerja dan Produktivitas Kerja. Bandung: CV. Mandar Maju

Sedarmayanti. 2014. Manajemen Sumber Daya Manusia, Reformasi Birokrasi, dan Manajemen Negeri Sipil Cetakan Ketujuh. Bandung: PT. Refika Aditama

Siagian. Sondang P. 2015. Manajemen Sumber Daya Manusia Ed. 1, Cet. 23. Jakarta : Bumi Aksara

Sopiah. 2008. Perilaku Organisasi. Yogyakarta: Andi

Sugiyono. 2012. Metode Penelitian Kuantitatif Kualitatif Dan R\&D. Bandung: Alfabeta

Sunyoto, Suyanto. 2011. Analisis Regresi untuk Uji Hipotesis. Yogyakarta: Caps Wibowo, Agung Edy dan Adji Djojo. 2012. Aplikasi Praktis SPSS dalam Penelitian, Edisi Kedua. Yogyakarta: Gava Media 